\title{
Article \\ Performance Enhancement of Self-Cleaning Cotton Fabric with ZnO NPs and Dicarboxylic Acids
}

\author{
Xinlei Ji ${ }^{\circ}$, Hong Li *, Yuan Qin and Jun Yan \\ Department of Textile and Material Engineering, Dalian Polytechnic University, Dalian 116034, China; \\ jx119980119@163.com (X.J.); qinyd163@163.com (Y.Q.); yanjun@dlpu.edu.cn (J.Y.) \\ * Correspondence: lihong@dlpu.edu.cn
}

Citation: Ji, X.; Li, H.; Qin, Y.; Yan, J. Performance Enhancement of Self-Cleaning Cotton Fabric with ZnO NPs and Dicarboxylic Acids. Crystals 2022, 12, 214. https:// doi.org/10.3390/cryst12020214

Academic Editor: Shujun Zhang

Received: 27 December 2021

Accepted: 29 January 2022

Published: 31 January 2022

Publisher's Note: MDPI stays neutral with regard to jurisdictional claims in published maps and institutional affiliations.

Copyright: (C) 2022 by the authors. Licensee MDPI, Basel, Switzerland. This article is an open access article distributed under the terms and conditions of the Creative Commons Attribution (CC BY) license (https:// creativecommons.org/licenses/by/ $4.0 /)$.

\begin{abstract}
In this paper, we explore the self-cleaning and washing durability of green-prepared $\mathrm{ZnO}$ NPs combined with cotton fabrics. Honeysuckle extract was used to prepare ZnO NPs with an average particle size of $15.3 \mathrm{~nm}$. Cotton fabrics were then treated with oxalic acid (OA), tartaric acid (TA), and succinic acid (SA) as cross-linking agents, sodium hypophosphite as a catalyst, and after that, the ZnO NPs were applied to the cross-linked cotton fabrics by the padding to prepare the selfcleaning cotton fabrics. The morphology and structure of the fabric samples were characterized using FTIR, scanning electron microscopy (SEM), Energy-dispersive X-ray spectroscopy (EDS), and XRD. The optical properties of the cotton fabric samples were discussed by UV-vis diffuse reflectance spectrum, and the self-cleaning performance, wrinkle recovery angle and ultraviolet protection performance of the cotton fabric samples were analyzed. The results showed that the carboxyl groups of TA, OA, and SA were esterified with hydroxyl groups of the cotton fiber and formed a film on the surface of the cotton fabrics. ZnO NPs were successfully loaded onto the cotton fabrics by strong electrostatic interaction, causing the improvement of the washing resistance of the cross-linked fabrics. In addition, compared with uncross-linked fabrics, the wrinkle recovery performance of the cross-linked fabrics had also been greatly improved, and the UV protection factor reached 50+, thus obtaining an excellent self-cleaning, multifunctional cotton-based textile with anti-wrinkle and anti-ultraviolet properties.
\end{abstract}

Keywords: cotton fabrics; ZnO NPs; cross-linked; washing resistance; self-cleaning

\section{Introduction}

Cotton fabrics are widely used in clothing and household products because of their good moisture absorption, breathability, and skin affinity [1]. However, cotton fabrics also have shortcomings such as easy staining, easy wrinkling, and poor UV resistance [2]. Bacteria easily breed on the surface of stained fabrics, leading to an increased risk of illness for users. The formation of wrinkles affects aesthetics and fabric comfort. Cotton fabrics have poor UV resistance, which accelerates the skin aging of users and even induces skin cancer. Therefore, it is particularly necessary to endow cotton fabrics with a certain degree of self-cleaning, anti-wrinkle, and anti-ultraviolet properties.

Nano $\mathrm{ZnO}$ is an inorganic metal oxide, which has non-toxicity and low cost. There are many ways to synthesize $\mathrm{ZnO}$, including the hydrothermal method, sol-gel method, and the precipitation method [3-6]. However, most of these methods involve using toxic chemicals and solvents harmful to human health and the environment. At present, the green preparation of nanoparticles with plant extracts such as aloe extract [7] and viburnum extract [8] have become a simple and eco-friendly preparation method. It was reported that green-prepared ZnO NPs have a smaller particle size and better optical properties [9].

Nano $\mathrm{ZnO}$ is also a semiconductor with a wide bandgap and high excitation binding energy [10]. When the nanoparticle is irradiated by light with energy greater than or equal to its forbidden bandwidth, the electrons are excited and transferred from the valence band 
to the conduction band, forming conduction band electrons $\left(\mathrm{e}^{-}\right)$, while the valence band leaves holes $\left(\mathrm{h}^{+}\right)$, then photo-generated electrons and holes are respectively captured by $\mathrm{O}_{2}$ and $\mathrm{H}_{2} \mathrm{O}$ molecules adsorbed on the surface, and finally, generate hydroxyl radicals $(\cdot \mathrm{OH})$. The free radicals have an oxidation potential of up to $2.7 \mathrm{eV}$, which has strong oxidizing properties and can indiscriminately oxidize and decompose the adsorbed pollutants $[3,11]$. So the incorporation of $\mathrm{ZnO}$ NPs with cotton fabric or polyester has been reported to develop photocatalytic self-cleaning textiles [12,13].

The washing resistance of functional textiles developed with nanoparticles is also a problem worthy of study. The use of cross-linking agents on the fabrics not only increases the functionality of fabrics but also improves the washing durability of fabrics. Dimethylol dihydroxy ethylene urea (DMDHEU) is one of the best cross-linkers for cotton, but it releases a high amount of toxic formaldehyde [14]. The polycarboxylic acid cross-linking agent is a formaldehyde-free crosslinking agent, which can not only give cotton fabrics easycare performance [15,16] but also effectively connect nanoparticles to cotton fabrics [17]. So, it is the most commonly used cross-linking agent. Majid has illustrated butane tetracarboxylic acid (BTCA) as a cross-linking agent to enhance the stability of Ag NPs on cotton fabrics [18]. However, the high cost and not cost-efficient of BTCA have lost its commercial viability; J L Zhu prepared the anti-wrinkle and antibacterial cotton fabric with good washing resistance by one-liquor finishing using a combination of polymaleic acid (PMA) and citric acid (CA) and Ag NPs [19]; Loghman Karimi adopted SA as a cross-linking agent to attach $\mathrm{TiO}_{2}$ on cotton, and revealed that the self-cleaning degree of the samples treated by the cross-linking was much higher than that of the non-cross-linked cotton [20].

Some studies have been done on the application of ZnO NPs in the development of selfcleaning fabrics [21], but there are few studies on the use of different dicarboxylic acids as cross-linking agents to immobilize $\mathrm{ZnO} N \mathrm{Ns}$ to improve their washing resistance. So, in this paper, a variety of dicarboxylic acids were used as cross-linking agents to immobilize $\mathrm{ZnO}$ NPs, and they were compared in detail to find the best dicarboxylic acid. First, ZnO NPs were prepared by plant extract-honeysuckle extract. Then three dicarboxylic acids (tartaric acid [TA], oxalic acid [OA], and succinic acid [SA]) were used to finish cotton fabrics using sodium hypophosphite (SHP) as the catalyst. Finally, the cotton fabrics were padded with a $\mathrm{ZnO}$ NPs solution. In this way, the cotton fabric not only obtained long-term self-cleaning properties but also greatly improved its anti-wrinkle and anti-ultraviolet properties.

\section{Experimental}

\subsection{Materials}

Pure cotton bleached woven fabrics ( 440 picks $/ 10 \mathrm{~cm} \times 421$ picks $/ 10 \mathrm{~cm}$ ) was obtained by Qingdao Coastal Textile Co., LTD., Shandong, China. Honeysuckle extract (80 mesh powder, containing $50 \%$ chlorogenic acid) was obtained by Shandong Deyan Chemical Co., LTD, Shandong, China. Zinc Nitrate Hexahydrate $\left(\mathrm{ZnNO}_{3} \cdot 6 \mathrm{H}_{2} \mathrm{O}\right)$ was obtained by Shanghai Guangrui Biotechnology Co., LTD., Shanghai, China. Methylene blue, Oxalic acid (OA), Tartaric acid (TA), succinic acid (SA), sodium hypophosphite monohydrate (SHP, $\mathrm{NaH}_{2} \mathrm{PO}_{2} \cdot \mathrm{H}_{2} \mathrm{O}$ ), as well as other chemicals were of reagent grade was obtained by Tianjin Cormier Chemical Reagent Co., LTD., Tianjin, China.

\subsection{Preparation of Self-Cleaning Cotton Fabric}

\subsubsection{Preparation of $\mathrm{ZnO} N P s$}

Zinc Nitrate Hexahydrate was used as the source of zinc in the experiment. First, Honeysuckle extract $(1 \mathrm{~g})$ was dissolved in $50 \mathrm{~mL}$ deionized water, centrifuged at $6000 \mathrm{r} / \mathrm{min}$ for $10 \mathrm{~min}$, and the supernatant was collected for use as honeysuckle extract solution. Secondly, $3 \mathrm{~mL}$ honeysuckle extract solution and $10 \mathrm{~mL}$ Zinc Nitrate Hexahydrate solution of $0.1 \mathrm{~mol} / \mathrm{L}$ were added into $37 \mathrm{~mL}$ deionized water and adjusted the $\mathrm{pH}$ to 7 with $0.1 \mathrm{~mol} / \mathrm{L} \mathrm{NaOH}$ solution, then heated in an oil liquor at $140{ }^{\circ} \mathrm{C}$ for $60 \mathrm{~min}$ to obtain a light yellow complex. Finally, the complexes were calcined at $300{ }^{\circ} \mathrm{C}$ for $3 \mathrm{~h}$ in a muffle furnace (atmosphere condition was air) to obtain $\mathrm{ZnO}$ NPs powders. Under the same 
conditions, a control experiment to prepare ZnO NPs without the addition of honeysuckle extract was carried out. Particle size analysis was performed by Transmission electron microscope (TEM).

\subsubsection{Cross-Linking of Cotton Fabric with Dicarboxylic Acids}

First, the cotton was pretreated (scoured with boiled water containing $2 \mathrm{~g} / \mathrm{L}$ soap flakes and $2 \mathrm{~g} / \mathrm{L}$ sodium carbonate at liquor ratio 1:30 [liquid ratio is a term used in textile dyeing and finishing, the ratio of the mass of cotton fabric to the volume of the solution, g: $\mathrm{mL}$, same as below] for $5 \mathrm{~min}$ ), and dried for later use. Secondly, the pretreated cotton fabrics were immersed in the prepared mixed solution of dicarboxylic acid (6\% o.w.s.) and SHP (4\% o.w.s.). The mixed solution was a mixed solution of binary carboxylic acid and catalyst sodium hypophosphate. The solvent is deionized water, and the solutes are dicarboxylic acid and SHP. The solvent is deionized water, and the solutes are dicarboxylic acid and SHP (liquor ratio 1:30 - the mass ratio of cotton fabric to the solution), which is stirred with an oscillating frequency of $120 \mathrm{r} / \mathrm{min}$ at $50{ }^{\circ} \mathrm{C}$ for $60 \mathrm{~min}$, then double-dipped and double-nipped [rolling residual rate $(80 \pm 1 \%)$, the same below]. The fabrics were dried at $70{ }^{\circ} \mathrm{C}$ for $30 \mathrm{~min}$ and cured at $160^{\circ} \mathrm{C}$ for $2 \mathrm{~min}$. Finally, the samples were washed with water for $5 \mathrm{~min}$ to remove excess reactants.

\subsubsection{Finishing of Cotton Fabric with ZnO NPs}

The cross-linked cotton fabrics with different dicarboxylic acids and a piece of uncrosslinked cotton fabric were immersed into $0.005 \mathrm{~mol} / \mathrm{L} \mathrm{ZnO}$ NPs solution with a liquor ratio of 1:30, respectively, and stirred at $50{ }^{\circ} \mathrm{C}$ for $60 \mathrm{~min}$. After two dips and two nips, the samples were put in an oven at $70^{\circ} \mathrm{C}$ for $60 \mathrm{~min}$ and taken out for later use. The samples were labeled TA- $\mathrm{ZnO} /$ cotton, $\mathrm{OA}-\mathrm{ZnO} /$ cotton, $\mathrm{SA}-\mathrm{ZnO} /$ cotton, and $\mathrm{ZnO} /$ cotton.

\subsection{Characterization of $\mathrm{ZnO} N \mathrm{NS}$ and Fabrics}

\subsubsection{Structure Characterization}

The X-ray diffraction patterns (XRD) of ZnO NPs and the cotton fabric samples were tested using an $\mathrm{X}$-ray diffractometer. The test conditions: tube voltage $40 \mathrm{kV}$, tube current $30 \mathrm{~mA}$, scanning speed: $5\left(^{\circ}\right) / \mathrm{min}, 2 \theta: 10 \sim 90^{\circ}$, The crystallite size of $\mathrm{ZnO}$ was calculated by Scherrer's formula [12].

$$
D=\frac{K \lambda}{\beta \cos \theta}
$$

where $K$ is the Scherrer constant, $0.89 ; \lambda$ is the $X$-ray wavelength at $0.1541 \mathrm{~nm} ; D$ is the size of the $\mathrm{ZnO} N P s$, and $\beta$ is the width at half-maximum; $\theta$ is the Bragg diffraction angle (in degrees).

The morphology and particle size of Zn NPs were tested by Transmission electron microscope (JEM-2100 (UHR), Beijing, China), and the accelerating voltage was $200 \mathrm{kV}$.

Fourier-transform infrared (FTIR) spectra of fabric samples were recorded through an FTIR spectrometer (FTIR920, Suzhou, China), test condition: KBr tablet, wave number range: $4000 \sim 400 \mathrm{~cm}^{-1}$. The surface morphologies of fabric samples were observed using a scanning electron microscope (SEM, Alpha300S, Dongguan, China);

The element of fabric samples was tested by an electronic energy spectrometer (EDS, HD-2001, Dongguan, China);

The content of the $\mathrm{Zn}$ element in the solution (wavelength band is $213 \mathrm{~nm}$ ) was detected by an inductively coupled plasma atomic emission spectrometer (ICP-AES, Guangzhou, China), the experiment was repeated 5 times, and the average value was obtained.

The water contact angle of the fabrics was measured by an automatic surface tensiometer (k100c, Shanghai, China). 


\subsubsection{Optical Performance}

Ultraviolet-visible (UV-vis) diffuse reflectance spectra of ZnO NPs and fabric samples were performed by a UV-vis spectrometer (Shimadzu, Japan), wave number range: $200 \sim 600 \mathrm{~nm}$.

\subsubsection{Self-Cleaning of Fabric}

To estimate the self-cleaning of the cotton fabrics finished with ZnO NPs, methylene blue, coffee, red wine, and soy sauce were selected as target organic pollutants. $1 \mathrm{~mL}$ methylene blue $(10 \mathrm{mg} / \mathrm{L})$ solution, coffee, red wine, and soy sauce (commercially available) were dropped on the surface of $5 \mathrm{~cm} \times 5 \mathrm{~cm}$ fabrics that were then placed in a dark place for $30 \mathrm{~min}$. After the stable absorption, the $\mathrm{K} / \mathrm{S}$ values of the fabrics were measured. Then they were exposed to simulated sunlight from an argon lamp that was $15 \mathrm{~cm}$ away from the fabrics for a period of time before the $\mathrm{K} / \mathrm{S}$ values of the fabrics were measured once again. The catalytic degradation rates of the fabrics were calculated according to the K/S values of the fabrics before and after the light, as shown in Formula (2).

$$
\xi=\frac{(K / S)_{0}-(K / S)_{t}}{(K / S)_{0}} \times 100 \%
$$

where $\xi$ is the degradation rate; $(K / S)_{0}$ is the $K / S$ value of the fabric before light; $(K / S)_{t}$ is the $K / S$ after $t$ hours of light.

To evaluate the self-cleaning durability of the fabrics, the fabrics stained by methylene blue were degraded with sunlight for $4 \mathrm{~h}$, and the degradation rate was calculated. Then the fabrics were washed according to the AATCC-61-2006 method. The degradation rate was calculated after 1-10 times washing circles. The SEM images and content of the $\mathrm{Zn}$ element of the samples after 10 times of washing were carried out.

\subsubsection{UV and Wrinkle Resistance of Fabric}

The UV resistance of the $\mathrm{ZnO} /$ Cotton, $\mathrm{OA}-\mathrm{ZnO} /$ cotton, $\mathrm{TA}-\mathrm{ZnO} /$ cotton, and SA$\mathrm{ZnO} /$ Cotton was measured using a Textile UV Performance Tester (YG(B)912E, Chengdu, China). The wrinkle recovery angle (WRA) of fabrics was tested using an automatic digital fabric crease elastomer (YG(B)541D-II, Xian, China).

\section{Results and Discussion}

\subsection{Characterization and Analysis of $\mathrm{ZnO} N P s$}

The TEM of ZnO NPs prepared without the addition of honeysuckle extract is shown in Figure 1b. It can be seen that ZnO NPs have large-area aggregation, large particle size, and poor effect, so they cannot be used for subsequent experiments. By comparison, Figure 1a shows that the ZnO NPS prepared by adding honeysuckle extract is uniformly dispersed, with a smaller particle size and better effect [19].

X-ray powder diffractograms for ZnO NPs are shown in Figure 2. It can be seen that the positions of the diffraction peaks of $31.78^{\circ}, 34.43^{\circ}, 36.26^{\circ}, 47.55^{\circ}, 56.61^{\circ}, 62.87^{\circ}, 66.40^{\circ}$, $67.97^{\circ}, 69.11^{\circ}, 72.58^{\circ}, 76.98^{\circ}$, and $81.40^{\circ}$ correspond to crystal planes (100), (002), (101), (102), (110), (103), (200), (112), (201), (004), (202) and (104), respectively, which were consistent with the values in the standard card (JCPD 89-0510). The (101) plane exhibited the highest relative intensity for the entire XRD pattern, suggesting anisotropic growth and preferred orientation of the crystallites, a typical feature of wurtzite-structured materials [22,23]. In addition, no other peaks were observed in the XRD pattern, indicating the high purity of the powders. The average crystallite size was determined by Scherrer's equation 1 (Equation (1)), and the calculated crystallite size was $15.3 \mathrm{~nm}$. The morphology of the $\mathrm{ZnO}$ NPs was characterized using TEM. It can be seen from Figure 1a (right) that most of the $\mathrm{ZnO}$ NPs prepared using the honeysuckle extract were approximately spherical, and the particle size from the TEM was smaller and close to the particle size calculated by the XRD pattern. 

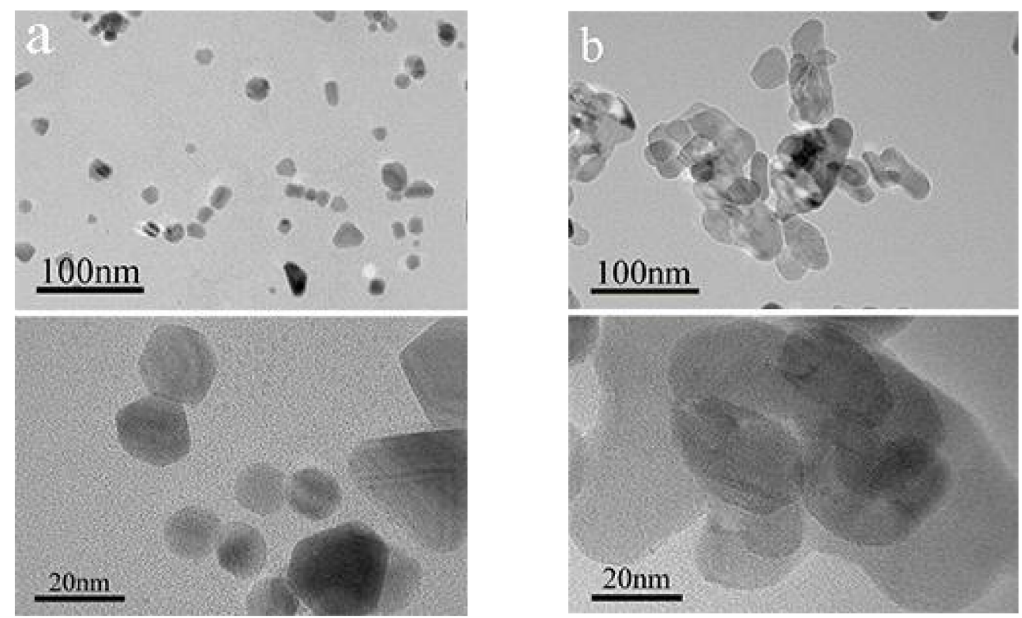

Figure 1. TEM images of ZnO NPs with honeysuckle extract added (a). TEM images of ZnO NPs without honeysuckle extract added (b).
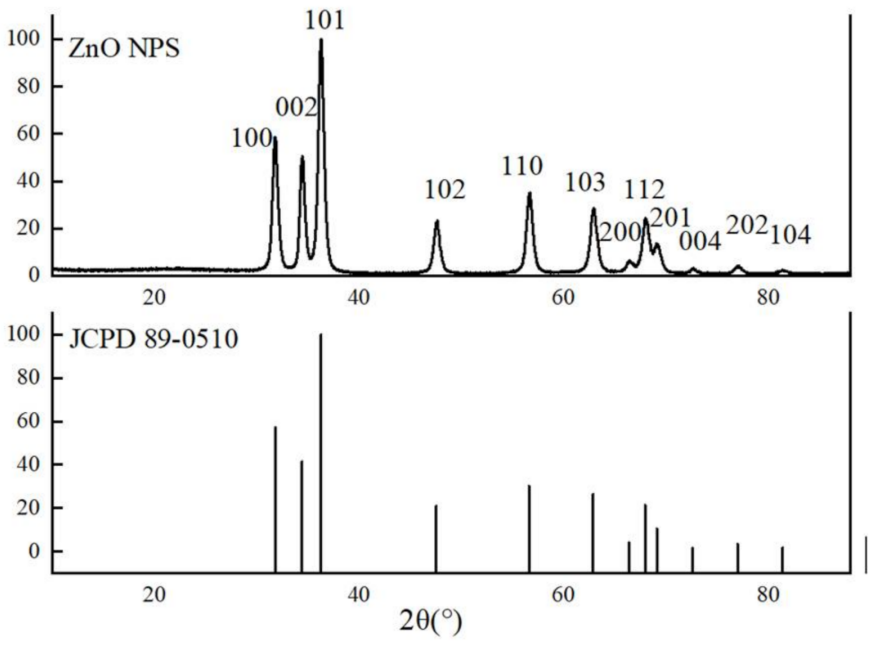

Figure 2. XRD patterns of ZnO NPs.

\subsection{FTIR Analysis of Fabrics}

FTIR analysis of the raw cotton, $\mathrm{TA}-\mathrm{ZnO} /$ cotton, OA-ZnO/cotton, and SA-ZnO/cotton was performed in Figure 3. Cellulose is an important component of cotton fabrics, the macromolecular chain of cellulose mainly contains $-\mathrm{OH}, \mathrm{C}-\mathrm{H},-\mathrm{CH}_{2-}$, and $\mathrm{C}-\mathrm{O}$ functional groups. As shown in Figure 3a, the peak at $3410 \mathrm{~cm}^{-1}$ is attributed to the $-\mathrm{OH}$ stretching vibration peak; the peak at $2901 \mathrm{~cm}^{-1}$ is attributable to the C-H stretching vibration absorption peak; the peak at $1371 \mathrm{~cm}^{-1}$ belongs to the $-\mathrm{CH}_{2}$ - flexural vibration absorption peak; the peak at $1058 \mathrm{~cm}^{-1}$ is attributable to the $\mathrm{C}-\mathrm{O}$ stretching vibration absorption peak; the peak at $1640 \mathrm{~cm}^{-1}$ belongs to the bending vibration peak of water adsorption [24]. It can be seen from the image of $\mathrm{ZnO} /$ cotton, $\mathrm{TA}-\mathrm{ZnO} /$ cotton, OA- $\mathrm{ZnO} /$ cotton, and SA$\mathrm{ZnO} /$ cotton in Figure $3 \mathrm{~b}-\mathrm{e}$ compared with the raw cotton that the peak at $435 \mathrm{~cm}^{-1}$ was stronger because the stretching vibration peak of $\mathrm{Zn}-\mathrm{O}$ bond is between $420 \sim 450 \mathrm{~cm}^{-1}$, showing that the cotton fabrics were loaded with $\mathrm{ZnO}$ NPs [25]. It can be seen from the images of TA-ZnO/cotton, OA-ZnO/cotton, and SA-ZnO/cotton in Figure 3c-e, a new peak appears at $1732 \mathrm{~cm}^{-1}$, it is attributable to the peaks of ester and carboxyl groups. It is evident that hydroxyl of cotton fiber was esterified with carboxyl in dicarboxylic acids, and carboxyl was introduced [26]. 


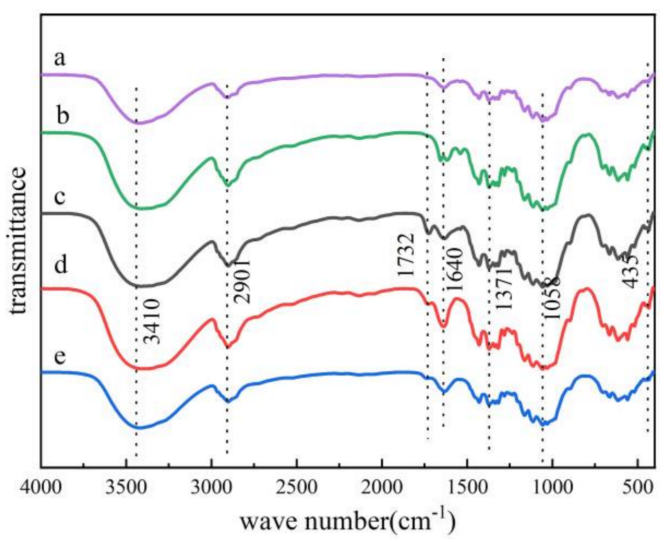

Figure 3. FTIR images of rawcotton (a), $\mathrm{ZnO} / \operatorname{cotton}(\mathbf{b}), \mathrm{OA}-\mathrm{ZnO} / \operatorname{cotton}(\mathbf{c}), \mathrm{TA}-\mathrm{ZnO} / \operatorname{cotton}(\mathbf{d})$ and $\mathrm{SA}-\mathrm{ZnO} / \operatorname{cotton}(\mathbf{e})$.

\subsection{SEM, EDS, and ICP-AES Analysis of Fabrics}

The scanning electron microscopy (SEM) images of raw cotton (a), ZnO/cotton (b), OA$\mathrm{ZnO} /$ cotton (c), TA-ZnO/cotton (d), and SA-ZnO/cotton (e) were presented in Figure 4. The content of the $\mathrm{Zn}$ element of cotton fabric loaded with $\mathrm{ZnO}$ NPs was measured by ICP-AES, and the result is shown in the upper right corner of the SEM image. The surface of the raw cotton fabric has many natural grooves, and it was not loaded with any particles. The surface of the $\mathrm{ZnO} /$ cotton fabric was loaded with a lot of spherical particles, and there was a slight agglomeration phenomenon. A layer of membrane structure formed on the OA-ZnO/cotton, $\mathrm{TA}-\mathrm{ZnO} /$ cotton, and SA-ZnO/cotton fabrics, of which only a few spherical particles were on their surfaces, were evenly distributed and smaller in size.
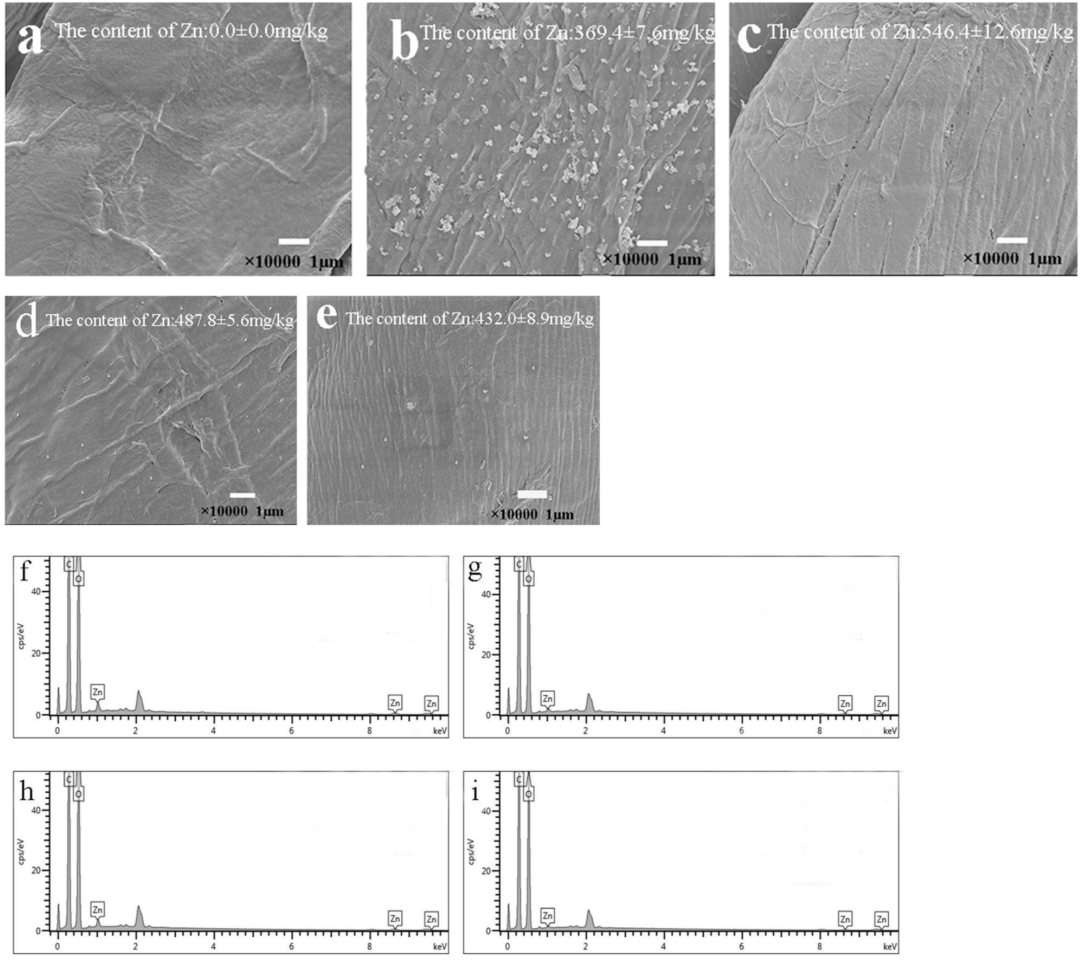

Figure 4. SEM images and Znelement contents of raw Cotton (a), $\mathrm{ZnO} / \operatorname{cotton}(\mathbf{b}), \mathrm{OA}-\mathrm{ZnO} /$ cotton (c), TA-ZnO/cotton (d), and SA-ZnO/cotton (e) and EDS spectra of $\mathrm{ZnO} /$ cotton (f), OA-ZnO/cotton (g), $\mathrm{TA}-\mathrm{ZnO} /$ cotton $(\mathbf{h})$ and $\mathrm{SA}-\mathrm{ZnO} / \operatorname{cotton}(\mathbf{i})$. 
As shown in Figure 4f-i of Energy Dispersive Spectroscopy (EDS), zinc and oxygen were two elements on the finished samples apart from the carbon related to the cotton fabrics, verifying that the ZnO NPs were successfully loaded on the fabrics.

SEM revealed that the number of nanoparticles on the cross-linked fabric surfaces was less than on $\mathrm{ZnO} /$ cotton. However, the ICP-AEM data showed that the content of the $\mathrm{Zn}$ element in the cross-linked cotton fabrics was more than that in the $\mathrm{ZnO} /$ cotton. This indicates that the carboxyl groups of the cross-linked fabric adsorbed more $\mathrm{ZnO}$ NPs through strong electrostatic force; due to the relatively high electronegativity of the oxygen atom in the $\mathrm{Zn}-\mathrm{O}$ bond of nano-zinc oxide, the electrons of zinc will be biased towards oxygen, which makes zinc positive. Then, because the oxygen on the carboxyl group shows a negative charge, the ZnO NPs are firmly loaded in the cotton fabric due to the electrostatic adsorption between anions and cations [27], and the ZnO NPsloaded on the cross-linked fabrics were mainly distributed under the film. In addition, the content of $\mathrm{ZnO}$ NPs on OA-ZnO/cotton $(546.4 \pm 12.6 \mathrm{mg} / \mathrm{kg})$ was more than that on TA$\mathrm{ZnO} / \operatorname{cotton}(487.8 \pm 5.6 \mathrm{mg} / \mathrm{kg})$ and SA-ZnO/cotton $(432.0 \pm 8.9 \mathrm{mg} / \mathrm{kg})$, which can be attributed to the more acidic potential and least pKa of oxalic acid (1.27) compared to that of two other dicarboxylic acids (pKa succinic acid $=4.21$, pKa Tartaric acid =3.04) [27]. The higher reactivity of oxalic acid resulted in a higher degree of esterification for the fabric, and as a result, the carboxyl content of fabric tended to increase, and the trend for electrostatic absorption of $\mathrm{ZnO}$ NPs increased [28]. The formation of ester cross-linkage of OA, TA, and $\mathrm{SA}$ with cellulose chain and $\mathrm{ZnO}$ and $\mathrm{OA}, \mathrm{TA}$, and SA linkage was shown in Figure 5 [29].

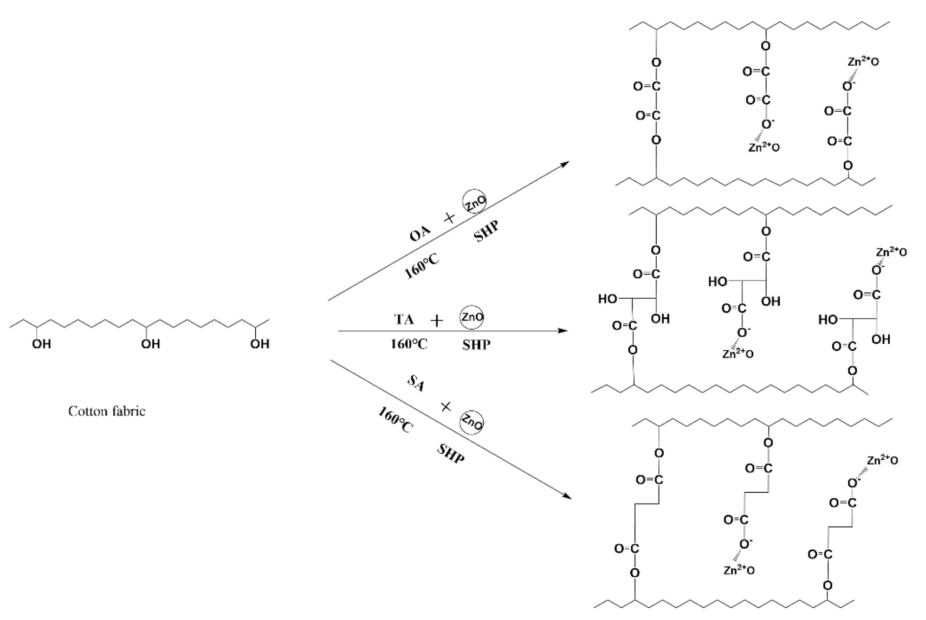

Figure 5. Schematic diagram of the cross-linked structure of OA, TA, and SA with cellulose chain and linkage of $\mathrm{ZnO}$ and $\mathrm{OA}, \mathrm{TA}$, and SA.

\subsection{XRD Analysis of Fabrics}

X-ray powder diffractograms of cotton fabrics before and after finishing with ZnO NPs are shown in Figure 6. It can be seen that the positions of the diffraction peaks of $14.95^{\circ}$, $16.49^{\circ}, 22.88^{\circ}$, and $34.34^{\circ}$ are related to cotton fibers, which correspond to the crystal plane diffraction of cellulose (101), (002), and (040) [30,31]. In addition, in Figure 6b-e, there are 7 other obvious sharp peaks and 2 weak diffraction peaks. The diffraction peaks of $31.78^{\circ}$, $34.43^{\circ}, 36.26^{\circ}, 47.55^{\circ}, 56.61^{\circ}, 62.87^{\circ}, 66.40^{\circ}, 67.97^{\circ}$, and $69.11^{\circ}$ correspond to the crystal planes of $\mathrm{ZnO}$ (100), (002), (101), (102), (110), (103), (200), (112), and (201), respectively [32], showing that the ZnO NPs were loaded on the cotton fabric. The average crystallite size was determined by Scherrer's equation (Equation 1), the calculated crystallite size was $21.2 \mathrm{~nm}$, and the size of the $\mathrm{ZnO}$ NPs loaded on the fabric became larger, the reason being that during the transfer of $\mathrm{ZnO}$ NPs from the treated solution to the fabrics, the treatments such as rolling, drying, and curing led to an agglomeration of the particles [19]. 


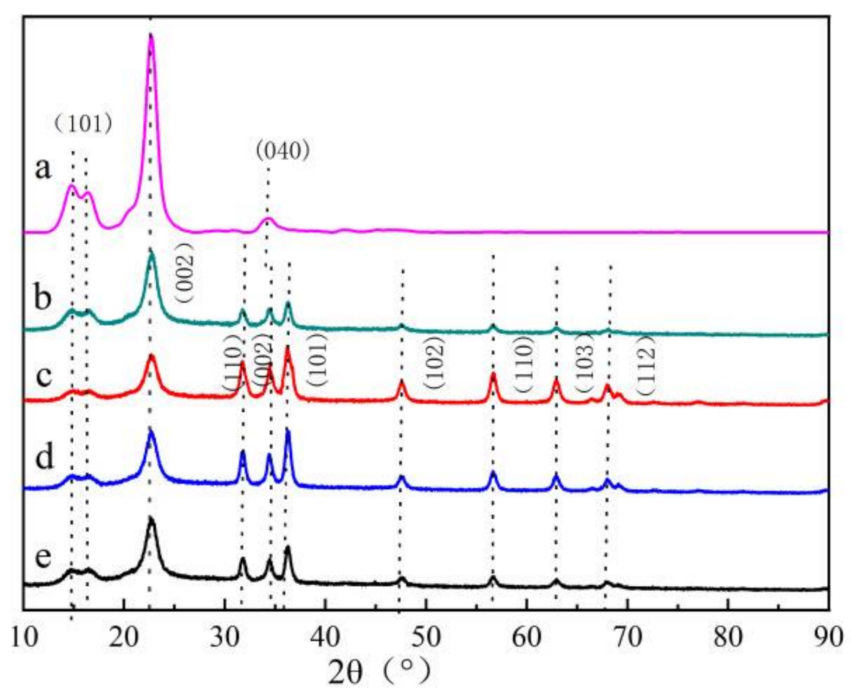

Figure 6. XRD patterns of raw cotton (a), $\mathrm{ZnO} /$ cotton (b), OA-ZnO/cotton (c), $\mathrm{TA}-\mathrm{ZnO} /$ cotton (d), and $\mathrm{SA}-\mathrm{ZnO} /$ cotton $(\mathbf{e})$.

\subsection{Optical Performance Analysis}

The UV-vis diffuse reflectance spectrum and the relationship curve between $(\alpha \mathrm{hv})^{1 / 2}$ and the hv of the cotton fabrics loaded with ZnO NPs are given in Figure 7.
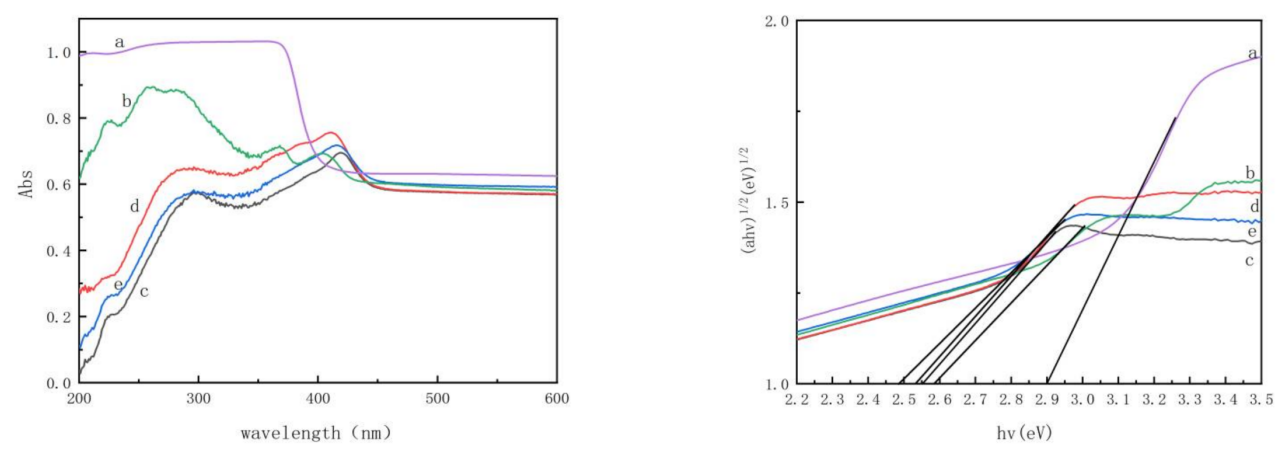

Figure 7. UV-vis diffuse reflectance spectra (left), (Ahv) ${ }^{1 / 2}$ and hv relationship curves (right): Raw cotton (a), $\mathrm{ZnO} /$ cotton (b), OA-ZnO/cotton (c), $\mathrm{TA}-\mathrm{ZnO} /$ cotton (d), and SA-ZnO/cotton (e).

It can be seen from Figure 7 left that in the ultraviolet region all fabrics show certain $\mathrm{UV}$ absorption properties, and the absorbance of $\mathrm{ZnO} /$ cotton was greater than that of the cross-linked cotton fabrics. This may be because the surface of $\mathrm{ZnO} /$ cotton adsorbs more $\mathrm{ZnO} N \mathrm{Ns}$, and $\mathrm{ZnO}$ NPs have stronger absorption of ultraviolet light. While ZnO NPs of the cross-linked cotton fabrics were mainly fixed under the cross-linked film, the film affects its UV absorption intensity. However, in the visible light region, the absorbance of the cross-linked fabrics was greater than that of $\mathrm{ZnO} /$ cotton, which may be because the cross-linking film on the surface of the fabric also partially absorbs visible light. $\mathrm{ZnO}$ NPs are used as a crystalline semiconductor. The light absorption near the band edge

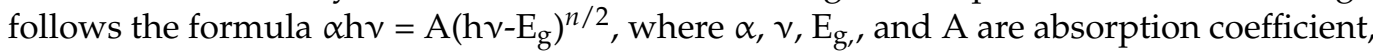
optical frequency, bandgap energy, and constant, respectively [33], where $n$ depends on the characteristics of semiconductor electronic transitions, that is direct transition $n=1$ and indirect transition $n=4$ for $\mathrm{ZnO}, n=4$. The relationship between $(\alpha \mathrm{h} v)^{1 / 2}$ and photon energy (hv) is shown on the right in Figure 7, where the intercept of the $x$-axis tangent is the forbidden bandwidth. The narrower the forbidden bandwidth of a semiconductor, the higher its light utilization. The right of Figure 7 shows that the bandgap width of $\mathrm{ZnO}$ prepared with honeysuckle extract was $2.90 \mathrm{eV}$, and $\mathrm{ZnO} /$ cotton was $2.57 \mathrm{eV}$. The bandgap of $\mathrm{ZnO} /$ cotton was narrower than that of $\mathrm{ZnO}$ NPs. This may be because cotton 
fabric also has a certain absorption effect on ultraviolet light, which increases its light utilization rate. Furthermore, the bandgap widths of $\mathrm{OA}-\mathrm{ZnO} /$ cotton, $\mathrm{TA}-\mathrm{ZnO} /$ cotton, and SA- $\mathrm{ZnO} /$ cotton were $2.55 \mathrm{eV}, 2.54 \mathrm{eV}$ and $2.48 \mathrm{eV}$, respectively. The bandgap widths of cross-linked cotton fabrics were narrower than that of the $\mathrm{ZnO} /$ cotton, indicating that cross-linking agents increased the utilization rate of cotton fabric to light.

\subsection{Self-Cleaning Performance Analysis}

The degradation rate of cotton fabrics after finishing with $\mathrm{ZnO}$ NPs was calculated by $\mathrm{K} / \mathrm{S}$ before and after light exposure. The cotton fabrics stained with pollutants were placed under simulated sunlight, and the K/S values were measured at intervals of $1 \mathrm{~h}$ for a total of $4 \mathrm{~h}$ of irradiation. According to Formula (2), the degradation rates of cotton fabric under different times of light exposure were calculated, and the results are shown in Figure 8.
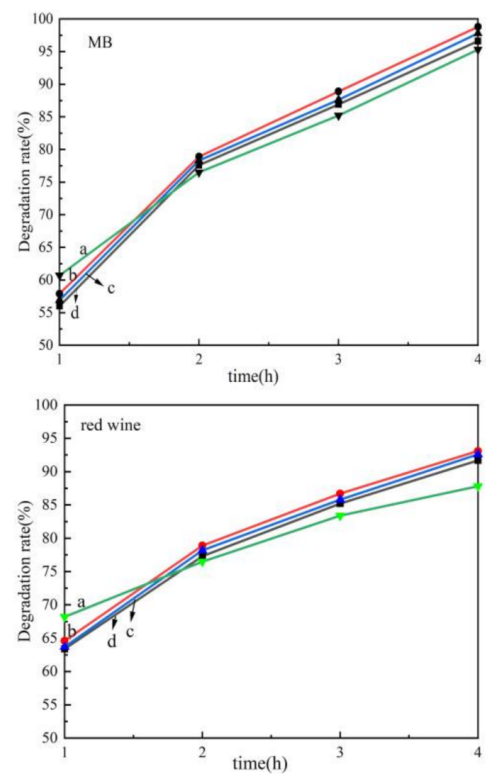
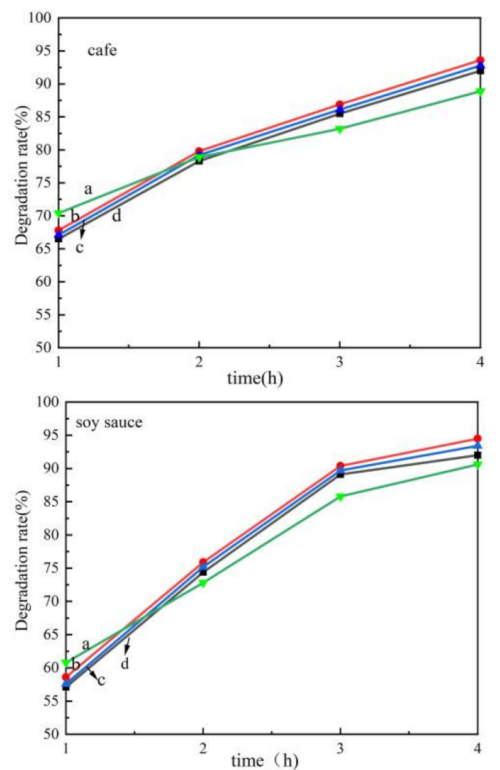

Figure 8. Degradation rates of $\mathrm{ZnO} /$ cotton (a), OA-ZnO/cotton (b), TA-ZnO/cotton (c), and SA$\mathrm{ZnO} /$ cotton $(\mathrm{d})$ to $\mathrm{MB}$, coffee, red wine, and soy sauce under different irradiation times.

Figure 8 shows that all samples have a self-cleaning effect on methylene blue, coffee, red wine, and soy sauce. The degradation rate of $\mathrm{ZnO} /$ cotton fabrics at the initial stage of illumination is higher than that of cross-linked cotton fabrics. This may be because most of the target pollutants were adsorbed on the $\mathrm{ZnO} /$ cotton surface during the initial stage of illumination. There were moreZnO NPs on the surface of $\mathrm{ZnO} /$ cotton, and a large number of free radicals generated by photoexcitation could contact the target pollutants and decompose them, so the degradation efficiency was higher, while for the cross-linked fabric, most of the target pollutants were adsorbed on the surface of the membrane during the initial stage of illumination. A few ZnO NPs were distributed on the surface of the membrane, so only fewer free radicals could directly contact the target pollutants, resulting in lower degradation efficiency. With the prolonged light time, the target pollutant diffused underneath the cross-linked membrane, at which time more free radicals could contact the pollutant and decompose it. Therefore, in the stage after contaminant diffusion has ended, the cross-linked cotton fabric had a high degradation rate of the target pollutant. In conclusion, improving the utilization rates of light of the cross-linked fabrics loaded with $\mathrm{ZnO} N$ Ps led to increased degradation rates.

To evaluate the washing resistance of the cotton fabrics loaded with ZnO NPs, the SEM images and Znelement content of the fabrics by ICP-AES after 10 cycles of washing were tested, as shown in Figure 9. 

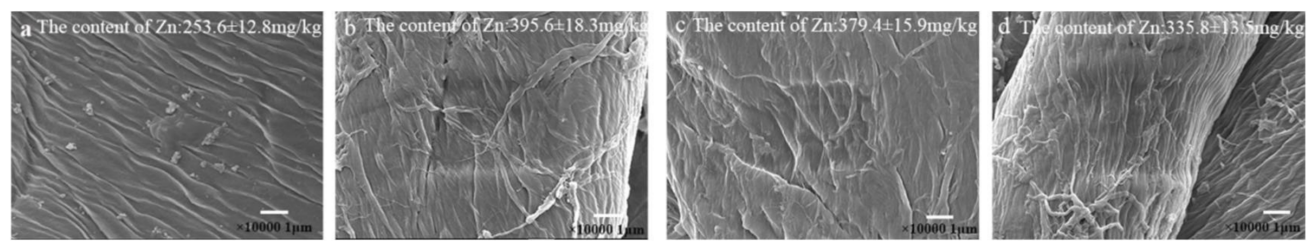

Figure 9. SEM images and $\mathrm{Zn}$ element contents of $\mathrm{ZnO} /$ cotton (a), OA-ZnO/cotton (b), TA$\mathrm{ZnO} /$ cotton (c) and SA-ZnO/cotton (d) after 10 cycles of washing.

It can be seen from Figure 9 that the number of particles adsorbed on the $\mathrm{ZnO} /$ cotton surface obviously decreased after 10 cycles of washings, and the size of the particles became significantly smaller in contrast with the unwashed $\mathrm{ZnO} /$ cotton (Figure $4 \mathrm{~b}$ ), indicating that during the washing process, the larger $\mathrm{ZnO}$ NPs were likely to fall off the surface of the fabric, and smaller particles have relatively firm linkage to the fabric and did not easily fall off the surface of the fabric. Moreover, the surface of cross-linked fabrics still has only a few particles, but the surface of the fabrics became rough. This may be because the continuous washing caused the membrane structure on the surface of the cotton fabrics to be damaged.

It can be seen from the ICP data that after 10 cycles of washing, the content of $\mathrm{Zn}$ element in the $\mathrm{ZnO} /$ cotton decreased from $369.4 \pm 7.6 \mathrm{mg} / \mathrm{kg}$ to $253.6 \pm 12.8 \mathrm{mg} / \mathrm{kg}$. This is because $\mathrm{ZnO} N$ Ps were adsorbed by $\mathrm{ZnO} /$ cottons via weak intermolecular forces, so they tended to fall off during washing. The content of a $\mathrm{Zn}$ element of OA-ZnO/cotton, TA$\mathrm{ZnO} /$ cotton, and SA-ZnO/cotton decreased from $546.4 \pm 12.6 \mathrm{mg} / \mathrm{kg}, 487.8 \pm 5.6 \mathrm{mg} / \mathrm{kg}$, and $432.0 \pm 8.9 \mathrm{mg} / \mathrm{kg}$ to $395.6 \pm 18.3 \mathrm{mg} / \mathrm{kg}, 379.4 \pm 15.9 \mathrm{mg} / \mathrm{kg}$ and $335.8 \pm 13.5 \mathrm{mg} / \mathrm{kg}$, respectively, indicating that the washing durability of the cross-linked cotton fabrics was greatly improved, possibly because the positively charged $\mathrm{Zn}^{2+}$ may be attracted by the negative charge of the carboxylate anion of the crosslinking agent [33]. The strong electrostatic attraction enforced the washing resistance of the fabric. Furthermore, the washing resistance of OA- $\mathrm{ZnO} /$ cotton was lower than that of $\mathrm{TA}-\mathrm{ZnO} /$ cotton and $\mathrm{SA}-\mathrm{ZnO} /$ cotton because the water contact angle $\left(35.5^{\circ}\right)$ of $\mathrm{OA}-\mathrm{ZnO} /$ cotton was lower than that of $\mathrm{TA}-\mathrm{ZnO} /$ cotton (46.34) and SA- $\mathrm{ZnO} / \operatorname{cotton}\left(41.25^{\circ}\right)$. Thus, the surface energy of OA-ZnO/cotton was higher, and the ZnO NPs were more likely to fall off during washing [28].

The degradation rates of the cotton fabrics after repeated washing and lighting for different cycles (0-10) were tested. The results are shown in Figure 10.

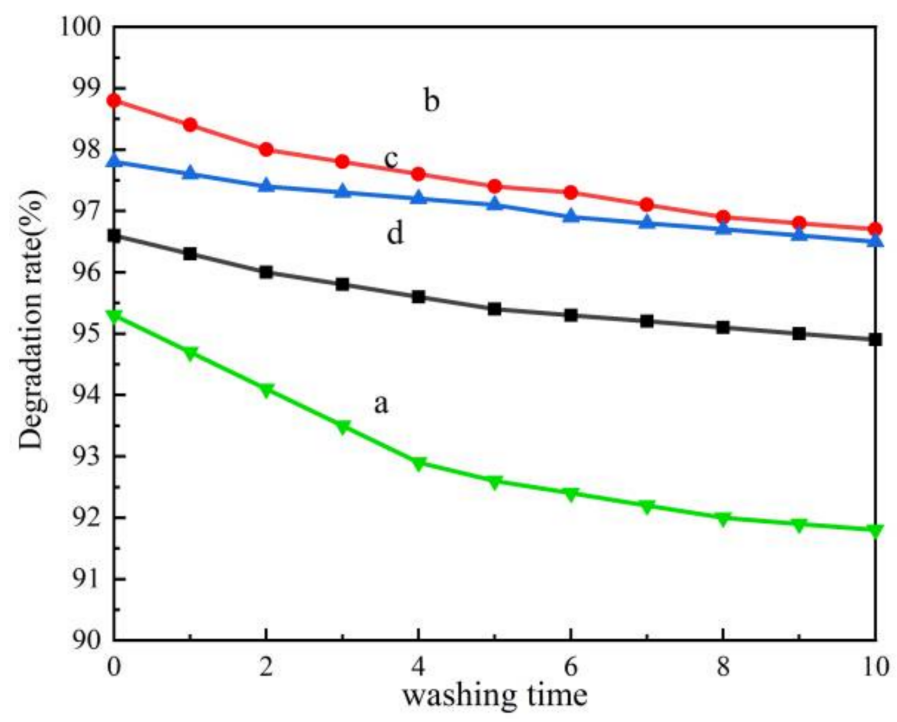

Figure 10. Degradation rates of methylene blue in $\mathrm{ZnO} / \operatorname{cotton}(\mathbf{a}), \mathrm{OA}-\mathrm{ZnO} /$ cotton (b), TA$\mathrm{ZnO} /$ cotton (c) and SA-ZnO/cotton (d) at different washing cycles.

Figure 10 shows that after 10 cycles washes, the degradation rate of $\mathrm{ZnO} /$ cotton decreased more than $\mathrm{OA}-\mathrm{ZnO} /$ cotton, $\mathrm{TA}-\mathrm{ZnO} /$ cotton, and $\mathrm{SA}-\mathrm{ZnO} /$ cotton. In addition, 
during the washing process of 1-4 cycles, the degradation rate of methylene blue by $\mathrm{ZnO}$ cotton decreased greatly. This is because the larger particles of ZnO NPs adsorbed on the cotton fabric fall off the fabric first, resulting in a significant decrease in the degradation rate of the fabric. In the next few washing processes, the degradation rate decreased slowly because the retained small-size particles have relatively strong adsorption with the fabric and were not easy to fall off. However, the degradation rate of cross-linked fabrics decreased gently throughout the washing.

\subsection{UV and Wrinkle Resistance of Fabric Analysis}

The anti-ultraviolet and wrinkle resistance performances of the cotton fabrics were analyzed, and the results are given in Table 1 . It can be seen from Table 1 that, compared with the raw cotton, the average UV transmittance of the UVA (320-400 nm) and UVB (280-320 nm) of $\mathrm{ZnO} /$ cotton, OA-ZnO/cotton, TA-ZnO/cotton, and SA-ZnO/cotton was significantly reduced, and the UPF values were significantly increased. It shows that the $\mathrm{ZnO}$ NPs loaded in the cotton fabrics greatly improved their UV resistance. This is because $\mathrm{ZnO} N$ Ps can absorb photons with bandgap energy greater than $2.90 \mathrm{eV}$, and the photon energy in the ultraviolet region meets this requirement. After ZnO NPs absorb ultraviolet light energy, it not only produces oxidative degradation but also greatly reduces the ultraviolet transmission rate of the fabrics. In addition, the reflection and scattering of ultraviolet rays through the interface formed by the NPs and the fabric were also strengthened, thereby enhancing the shielding effect of the cotton fabrics to ultraviolet rays and improving its antiultraviolet performance [19]. According to the requirements of GB/T18830-2009, when the UPF value of the textile is more than 40 , and its UVAtransmittance is less than $5 \%$, it is considered as an anti-ultraviolet product with a mark of $40+$. So $\mathrm{ZnO} /$ cotton, OA-ZnO/cotton, $\mathrm{TA}-\mathrm{ZnO} /$ cotton, and SA-ZnO/cotton can be called anti-ultraviolet textiles.

Table 1. UV and wrinkle resistance of the Raw Cotton, $\mathrm{ZnO} /$ Cotton, SA-ZnO/Cotton, OA$\mathrm{ZnO} /$ cotton, and $\mathrm{TA}-\mathrm{ZnO} /$ cotton.

\begin{tabular}{cccccc}
\hline \multirow{2}{*}{ Sample } & \multicolumn{2}{c}{ Average UV Transmittance (\%) } & & UPF & WRA $\left(\mathbf{W}+\mathbf{F}\left({ }^{\circ}\right)\right)$ \\
\cline { 2 - 3 } & UVA & UVB & & \\
\hline Raw Cotton & 29.98 & 15.65 & 5.36 & 120.1 \\
ZnO/Cotton & 1.77 & 1.49 & $50+$ & 151.6 \\
OA-ZnO/cotton & 1.50 & 1.24 & $50+$ & 171.6 \\
TA-ZnO/cotton & 1.30 & 1.02 & $50+$ & 193.2 \\
SA-ZnO/cotton & 1.27 & 0.92 & $50+$ & 225.7 \\
\hline
\end{tabular}

In addition, compared with raw cotton, the wrinkle recovery angles of cotton fabrics loaded with $\mathrm{ZnO}$ NPs were improved. The wrinkle recovery angle of $\mathrm{ZnO} /$ cotton was slightly increased by $26.23 \%$. However, the wrinkle recovery angles of OA- $\mathrm{ZnO} /$ cotton, $\mathrm{TA}-\mathrm{ZnO} /$ cotton, and SA-ZnO/cotton were considerably increased by $87.93 \%, 51.21 \%$, and $60.87 \%$, respectively. This is due to the cross-linking of OA, SA, and TA with cotton fabrics effectively preventing the slippage of the cellulose macromolecular chain so that the cross-linked fabric has better resistance to deformation.

\section{Conclusions}

In this paper, honeysuckle extract was used to prepare $\mathrm{ZnO}$ NPs with an average particle size of $15.3 \mathrm{~nm}$. Three dicarboxylic acids of OA, TA, and SA were adopted to cross-link cotton fabrics. Then $\mathrm{ZnO}$ NPs were applied to the cotton fabrics before and after cross-linking by the padding method to obtain the self-cleaning $\mathrm{ZnO} /$ cotton, OA$\mathrm{ZnO} /$ cotton, $\mathrm{TA}-\mathrm{ZnO} /$ cotton, and $\mathrm{SA}-\mathrm{ZnO} /$ cotton. Through structure characterization and performance analysis of samples, we found that all the cotton fabrics finished with $\mathrm{ZnO}$ NPs have a high degradation ability to methylene blue, coffee, red wine, and soy sauce. Compared with the $\mathrm{ZnO} /$ cotton, the bandgap width of the cross-linked fabrics became narrower, the utilization rate to light was improved, and better self-cleaning performance 
was exhibited. A film formed on the surface of the cross-linked cotton fabrics, and $\mathrm{ZnO}$ NPs were mainly fixed under the film through strong electrostatic force, while the $\mathrm{ZnO}$ $\mathrm{NPs}$ on $\mathrm{ZnO} /$ cotton was adsorbed on the surface of the fabric through relatively weak van der Waals force, so the cross-linked cotton fabrics had better washing resistance. Moreover, for the cross-linked cotton fabrics, the adsorption amount of $\mathrm{ZnO} N$ ss of OA-ZnO/cotton was highest, the washing resistance of $\mathrm{TA}-\mathrm{ZnO} /$ cotton was best, and after cross-linkage, the UV and wrinkle resistance of cotton fabrics was greatly improved.

Author Contributions: X.J., H.L. and J.Y. designed the experiments. X.J. and Y.Q. performed the experiments. X.J. analyzed the data. X.J. and Y.Q. wrote the paper. All authors have read and agreed to the published version of the manuscript.

Funding: This work was supported by the project of "Five Strategies" of Education Service of Industrial Technology Research Institute of Liaoning Universities (No. 2018LY027).

Institutional Review Board Statement: Not applicable.

Informed Consent Statement: Not applicable.

Data Availability Statement: The data presented in this study are available on request from the corresponding author.

Conflicts of Interest: The authors declare no conflict of interest.

\section{References}

1. Saxena, A.; Tripathi, R.M.; Singh, R.P. Biological synthesis of silver nanoparticles by using onion (Allium cepa) extract and their antibacterial activity. Dig. J. Nanomater. Biostruct. 2010, 5, 427-432.

2. Cruz, D.; Fale, P.L.; Mourato, A.; Vaz, P.D.; Luisa, S.M.; Lino, A.R.L. Preparation and physicochemical characterization of Ag nanoparticles biosynthesized by Lippia citriodora (lemon verbena). Colloid Surf. B 2010, 81, 67-73. [CrossRef] [PubMed]

3. Gunalan, S.; Sivaraj, R.; Rajendran, V. Green synthesized ZnO nanoparticles against bacterial and fungal pathogens. Prog. Nat. Sci. Mater. Int. 2012, 22, 693-700. [CrossRef]

4. Khun, K.; Ibupoto, Z.H.; Chey, C.O.; Lu, J.; Nur, O.; Willander, M. Comparative study of ZnO nanorods and thin films for chemical and biosensing applications and the development of $\mathrm{ZnO}$ nanorods based potentiometric strontium ion sensor. Appl. Surf. Sci. 2013, 268, 37-43. [CrossRef]

5. Vanaja, A.; Srinivisa Rao, K. Effect of Co Doping on Structural and Optical Properties of Zinc Oxide Nanoparticles Synthesized by Sol-Gel Method. Adv. Nanopart. 2016, 5, 83-89. [CrossRef]

6. Tang, E.; Tian, B.Y.; Zheng, E.; Fu, C.Y.; Cheng, G.X. Preparation of zinc oxide nanoparticle via uniform precipitation method and its surface modification by methacryloxypropyltrimethoxysilane. Chem. Eng. Commun. 2008, 195, 479-491. [CrossRef]

7. Sangeetha, G.; Rajeshwari, S.; Venckatesh, R. Green synthesis of zinc oxide nanoparticles by aloe barbadensis miller leaf extract: Structure and optical properties. Mater. Res. Bull. 2011, 46, 2560-2566. [CrossRef]

8. Taşdemir, A.; Aydin, R.; Akkaya, A.; Akman, N.; Altınay, Y.; Çetin, H.; Şahin, B.; Uzun, A.; Ayyıldız, E. A green approach for the preparation of nanostructured zinc oxide: Characterization and promising antibacterial behaviour. Ceram. Int. 2021, 47, 19362-19373. [CrossRef]

9. Wang, L.; Chang, L.X.; Zhao, B.; Yuan, Z.Y.; Shao, G.; Zheng, W.J. Systematic investigation on morphologies, forming mechanism, photocatalytic and photoluminescent properties of $\mathrm{ZnO}$ nanostructures constructed in ionic liquids. Inorg. Chem. 2008, 47, 1443-1452. [CrossRef]

10. Deng, Z.W.; Chen, M.; Gu, G.X.; Wu, L.M. A facile method to fabricate ZnO hollow spheres and their photocatalytic property. J. Phys. Chem. B 2008, 112, 16-22. [CrossRef]

11. Zuo, D.Y.; Li, G.Q.; Ling, Y.L.; Cheng, S.J.; Xu, J.; Zhang, H.W. Durable UV-blocking Property of Cotton Fabrics with Nanocomposite Coating Based on Graphene Oxide/ZnO Quantum Dot via Water-based Self-assembly. Fibers Polym. 2021, 22, 1837-1843. [CrossRef]

12. Amani, A.; Montazer, M.; Mahmoudirad, M. Synthesis of applicable hydrogel corn silk/ZnO nanocomposites on polyester fabric with antimicrobial properties and low cytotoxicity. Int. J. Biol. Macromol. 2019, 123, 1079-1090. [CrossRef]

13. Ankamwar, B.; Chahudhary, M.; Sastry, M. Gold nanotriangles biologically synthesized using tamarind leaf extract and potential application in vapor sensing. Synth. React. Inorg. Met.-Org. Nano-Met. Chem. 2005, 35, 19-26. [CrossRef]

14. Hossain, M.F.; Asaduzzaman, M.U. Optimum Concentration of Cross-Linking Agent for Crease-Resistant Finishing Using DMDHEU on Knit and Woven Fabric in the Field of Ease Care Durable Press. J. Text. Sci. 2016, 5, 74-81.

15. Cai, X.Y.; Li, H.; Zhang, L.; Yan, J. Dyeing Property Improvement of Madder with Polycarboxylic Acid for Cotton. Polymers 2021, 13, 3289. [CrossRef]

16. Kumar, R.R.; Yazhini, K.B.; Prabu, H.G.; Zhou, Q.X. Polyfunctional Application on Modified Cotton Fabric. Natl. Acad. Sci. Lett. 2019, 42, 475-478. [CrossRef] 
17. Dong, Y.M.; Liu, X.Y.; Liu, J.; Yan, Y.; Liu, X.; Wang, K.; Li, J. Evaluation of anti-mold, termite resistance and physical-mechanical properties of bamboo cross-linking modified by polycarboxylic acids. Constr. Build. Mater. 2021, 272, 121953. [CrossRef]

18. Majid, M.; Alimohammadi, F.; Shamei, A.; Rahimi, M.K. Durable antibacterial and cross-linking cotton with colloidal silver nanoparticles and butane tetracarboxylic acid without yellowing. Colloid Surf. B 2012, 89, 196-202.

19. Zhu, J.L.; Li, H.; Wang, Y.; Wang, Y.S.; Yan, J. Preparation of Ag NPs and Its Multifunctional Finishing for Cotton Fabric. Polymers 2021, 13, 1338. [CrossRef]

20. Mirjalili, M.; Karimi, L. Photocatalytic Degradation of Synthesized Colorant Stains on Cotton Fabric Coated with Nano TiO $2 . J$ Fiber Bioeng. Inform. 2010, 3, 208-215. [CrossRef]

21. Tran, V.H.T.; Lee, B.K. Development of multifunctional self-cleaning and UV blocking cotton fabric with modification of photoactive $\mathrm{ZnO}$ coating via microwave method. J. Photochem. Photobiol. A 2017, 338, 13-22. [CrossRef]

22. Uribe López, M.C.; Hidalgo López, M.C.; LópezGonzález, R.; Frías Márquez, D.M.; Núñez Nogueira, G.; Hernández Castillo, D.; Alvarez Lemus, M.A. Photocatalytic activity of $\mathrm{ZnO}$ nanoparticles and the role of the synthesis method on their physical and chemical properties. J. Photochem. Photobiol. A 2021, 404, 112866. [CrossRef]

23. Peng, Y.G.; Ji, J.L.; Zhao, X.Y.; Wan, H.X.; Chen, D.J. Preparation of ZnOnanopowder by a novel ultrasound assisted non-hydrolytic sol-gel process and its application in photocatalytic degradation of C.I. Acid Red 249. Powder Technol. 2013, 233, 325-330. [CrossRef]

24. Cao, Y.; Tan, H.M. Structural characterization of cellulose with enzymatic treatment. J. Mol. Struct. 2004, 705, 189-193. [CrossRef]

25. Mahamuni, P.P.; Patil, P.M.; Dhanavade, M.J.; Badiger, M.; Shadija, P.G.; Lokhande, A.C. Synthesis and characterization of zinc oxide nanoparticles by using polyol chemistry for their antimicrobial and antibiofilm activity. Biochem. Biophys. Rep. 2018, 17, 71-80. [CrossRef] [PubMed]

26. Sarwar, N.; Ashraf, M.; Mohsin, M.; Rehman, M.; Younus, A.; Javid, A.; Iqbal, K.; Riaz, S. Multifunctional Formaldehyde Free Finishing of Cotton by Using Metal Oxide Nanoparticles and Ecofriendly Cross-Linkers. Fibers Polym. 2019, 20, $2326-2333$. [CrossRef]

27. Cornils, B.; Lappe, P. Dicarboxylic Acids, Aliphatic. In Ullmann's Encyclopedia of Industrial Chemistry; Wiley-VCH: Weinheim, Germany, 2006.

28. Khajavi, R.; Berendjchi, A. Effect of Dicarboxylic Acid Chain Length on the Self-Cleaning Property of $\mathrm{Nano}^{-T i O}{ }_{2}$-Coated Cotton Fabrics. ACS Appl. Mater. Interfaces 2014, 6, 18795-18799. [CrossRef] [PubMed]

29. Karimi, L.; Mirjalili, M.; Yazdanshenas, M.E.; Nazari, A. Effect of $\mathrm{Nano} \mathrm{TiO}_{2}$ on Self-cleaning Property of Cross-linking Cotton Fabric with Succinic Acid under UV Irradiation. Photochem. Photobiol. 2010, 86, 1030-1037. [CrossRef] [PubMed]

30. Siami, A.M.; Majid, M. Clean Sono-synthesis of ZnO on Cotton/Nylon Fabric Using Dopamine: Photocatalytic, Hydrophilic, Antibacterial Features. Fibers Polym. 2021, 22, 97-108.

31. Hu, C.; Zhou, Y.Y.; Zhang, T.; Jiang, T.J.; Meng, C.; Zeng, G.S. Morphological, Thermal, Mechanical, and Optical Properties of Hybrid Nanocellulose Film Containing Cellulose Nanofiber and Cellulose Nanocrystals. Fibers Polym. 2021, 22, 2187-2193. [CrossRef]

32. Gokula, K.P.; Muthukumaran, S.; Raja, V. Structural, energy gap tuning, photoluminescence and magnetic properties of Sn-doped $\mathrm{Zn}_{0.96} \mathrm{Ni}_{0 \cdot 04} \mathrm{O}$ nanostructures. J. Lumin. 2021, 238, 118258.

33. Zhang, X.; Ai, Z.H.; Jia, F.J.; Jia, F.L.; Zhang, L.Z. Generalized One-Pot Synthesis, Characterization, and Photocatalytic Activity of Hierarchical BiOX $(X=$ Cl, Br, I) Nanoplate Microspheres. J. Phys. Chem. C 2008, 112, 747-753. [CrossRef] 